Revue d'histoire de l'Amérique française

ZAS REVUE D.HISTOIRE DE L'AMÉRIQUE FRANÇAISE

\title{
Monseigneur Laflèche et les ultramontains
}

\section{Robert Rumilly}

Volume 16, numéro 1, juin 1962

URI : https://id.erudit.org/iderudit/302173ar

DOI : https://doi.org/10.7202/302173ar

Aller au sommaire du numéro

Éditeur(s)

Institut d'histoire de l'Amérique française

ISSN

0035-2357 (imprimé)

1492-1383 (numérique)

Découvrir la revue

Citer cet article

Rumilly, R. (1962). Monseigneur Laflèche et les ultramontains. Revue d'histoire de l'Amérique française, 16(1), 95-101. https://doi.org/10.7202/302173ar d'utilisation que vous pouvez consulter en ligne.

https://apropos.erudit.org/fr/usagers/politique-dutilisation/ 


\section{MONSEIGNEUR LAFLĖCHE ET LES ULTRAMONTAINS *}

L'abbé Louis-François Laflèche, missionnaire en Saskatchewan - à l'île-à-la-Crosse, à deux mois de voyage en embarcation de Saint-Boniface, avant-poste de la civilisation - eut pour compagnon un jeune Oblat, le Père Alexandre-Antonin Taché, et les deux prêtres se lièrent d'une amitié fraternelle. Le Père Taché fut le premier disciple de l'abbé Laflèche. Il disait de son aîné: «C'est un prêtre selon le cœur de Dieu. »

L'existence à l'île-à-la-Crosse comportait de dures privations. L'abbé Laflèche en garda une semi-infirmité - une légère claudication - pour le reste de sa vie. Prêtre d'une grande intelligence, mais en même temps d'une véritable humilité, il refusa d'être nommé coadjuteur de Mgr Provencher, en prétextant son «infirmité ». Il fit désigner le Père Taché, en insistant sur cette raison: la nomination du Père Taché aura l'avantage d'attacher les Oblats aux missions de l'Ouest.

Renvoyé dans l'Est pour raisons de santé, l'abbé Laflèche enseigna au Séminaire de Nicolet - son Alma Mater - auquel il était très dévoué. C'était d'ailleurs un professeur-né, parlant très facilement, dégageant sur tout sujet les grandes lignes, les idées générales, la signification foncière. Il devint préfet des études, et en même temps vicaire général de Mgr Cooke, évêque des Trois-Rivières. En 1859, il fut élu supérieur. A ce titre il combattit vainement le projet de fondation du Séminaire des Trois-Rivières. Enfin Mgr Cooke arrache l'abbé Laflèche au Séminaire de Nicolet, pour le nommer administrateur du diocèse des Trois-Rivières, menacé d'une crise financière. L'abbé Laflèche s'acquitte de sa tâche à merveille. C'était dans une période d'effervescence libérale en Europe, lors des furieux assauts livrés contre le pouvoir temporel du pape. L'abbé Laflèche suivit Mgr Bourget, grand champion canadien de la suprématie pontificale. Le collaborateur de Mgr Cooke exposa dès ce moment

\footnotetext{
* Travail présenté lors de la réunion générale de l'Institut d'Histoire de l'Amérique française, le 14 avril 1962.
} 
ses idées sur les rapports de la société civile avec la religion, dans une série d'articles du Journal des Trois-Rivières, réunis en un petit volume.

\section{LE CONFLIT DE PRINCIPES}

Il y condamne le libéralisme qui, écrit-il, « commet l'erreur fondamentale de vouloir édifier une société sur d'autres principes que les principes religieux ». Il écrit:

Les électeurs n'exercent pas seulement un droit; ils remplissent un devoir, dont ils sont responsables devant Dieu.

Le prêtre a donc le devoir de les guider.

C'est une erreur condamnée par la raison, par l'histoire et par la révélation, de dire que la politique est un terrain où la religion n'a pas le droit de mettre le pied, et où l'Eglise n'a rien à voir.

Il insistait aussi, en toute occasion, sur la solidarité de la famille, de la nation, de la langue et de la foi.

Nommé coadjuteur avec future succession à la fin de 1866, il affermit son désir de préserver le peuple canadien-français de la vague irréligieuse qui déferlait sur l'Europe. Les grands conflits idéologiques qui passionnaient les milieux intellectuels d'Europe entraînaient en effet des répercussions au Canada français. Un prêtre français, Mgr Gaume, demandait une réforme de l'enseignement, imprégné de paganisme, affirmait-il, et auquel on devrait imprimer un sens plus chrétien. Les adversaires de Mgr Gaume le taxaient d'intransigeance, d'étroitesse d'esprit, et préconisaient la conciliation avec les idées dites «modernes ». La querelle se propage au Canada. Les gaumistes dominent autour de Mgr Bourget, à Montréal; les antigaumistes dominent au Séminaire et à l'Archevêché de Québec.

Deux familles d'esprit s'opposent. Le grand vicaire Laflèche ne s'y trompe pas. Il ramène tous les débats à quelque opposition majeure - et irréductible: la vérité et l'erreur; l'ordre et l'anarchie; l'autorité et la révolution; le catholicisme et le libéralisme. Pie IX a condamné dans le Syllabus (1864) le libéralisme catholique et un certain nombre d'idées dites « modernes ». Le grand vicaire Laflèche estime nécessaire la lutte de l'Église, la défense de l'Église contre le libéralisme rationaliste, 
issu de Voltaire, de Jean-Jacques Rousseau, des faux principes de 1789. Car l'attitude des Bourget et des Laflèche, comme l'attitude de leurs émules européens, fut dans une large mesure une réaction de défense contre ce qui leur apparaissait comme une vaste offensive antireligieuse. C'était l'époque de l'Institut Canadien, de l'affaire Guibord, des contestations d'élection pour « influence indue », de la propagande chiniquiste.

L'abbé Laflèche assistait au concile du Vatican lorsque la mort de Mgr Cooke fit de lui, automatiquement, l'évêque des Trois-Rivières. La proclamation de l'infaillibilité pontificale le remplit de joie et renforça son zèle.

Les luttes de Mgr Laflèche furent d'abord celles de Mgr Bourget. L'évêque de Montréal passait pour l'inspirateur du journal Le Nouveau-Monde, qui voulait soumettre les hommes politiques aux directives romaines et épiscopales. Il se heurtait au groupe de l'Institut Canadien. Il se heurtait aussi à GeorgesEtienne Cartier, chef civil prestigieux et autoritaire.

Les disciples de Mgr Bourget, réunis chez Alphonse Desjardins, publièrent le Programme Catholique en 1871. S'appuyant sur une lettre pastorale de Mgr Laflèche, ils proclamaient la primauté de l'Église sur l'État, le droit pour l'Église de donner des instructions aux hommes politiques et aux électeurs. Les 《programmistes » ou « ultramontains » ne visaient pas à constituer un parti politique proprement dit, mais plutôt à agir sur les partis. Ils favorisaient en principe le parti conservateur, mais voulaient lui imposer l'observation du Programme. L'évêque de Montréal et l'évêque des Trois-Rivières approuvèrent le Programme Catholique. Au contraire, Mgr Taschereau, archevêque de Québec, ne cachait pas sa réprobation.

L'opposition des deux tendances, des deux familles d'esprits, est bien établie. Là-dessus se greffent des conflits particuliers.

\section{LES CONFLITS PARTICULIERS}

D'abord le parti politique portant l'étiquette libérale craignit une confusion avec le libéralisme religieux. De fait, il comptait bien des libéraux « avancés », tel le groupe de l'Institut Canadien, 
envers qui les accusations des ultramontains étaient justifiées. Ensuite Mgr Laflèche, évêque des Trois-Rivières, reprit un projet de Mgr Cooke, qui voulait fusionner les deux séminaires de Nicolet et des Trois-Rivières, pour conserver une seule institution, au chef-lieu du diocèse. Nicolet résista.

Enfin les Jésuites, appuyés par Mgr Bourget, demandaient à la législature l'autorisation de fonder une université à Montréal. L'Université Laval, voulant rester la seule université catholique du Canada, combattait cette démarche, et Mgr Taschereau, ancien recteur de Laval, encourageait son université. Le conflit universitaire se compliqua. Il existait à Montréal, depuis 1843, une École de Médecine et de Chirurgie, fondée par des Anglo-protestants mais devenue graduellement canadienne-française et catholique. N'ayant pas réussi à s'affilier à l'Université Laval, l'École avait dû, pour pouvoir décerner des diplômes, s'affilier à l'Université Victoria, de Cobourg, Ontario. C'est pourquoi on l'appelait aussi l'École Victoria. Mais l'accord de l'école montréalaise et de l'université ontarienne stipulait que l'École de Médecine et de Chirurgie restait et resterait catholique, sous le contrôle de l'évêque de Montréal. En somme le lien entre l'École et l'université de Cobourg ne fut jamais qu'une suzeraineté toute théorique.

Quand Mgr Bourget désira installer à Montréal une université indépendante, il fut tacitement convenu que l'École deviendrait la faculté de Médecine de cette université. Le Saint-Siège décidant que Montréal aurait seulement une succursale de l'Université Laval, l'École de Médecine dut — de mauvais gré se laisser affilier à Laval. Mais les frictions ne tardèrent pas et aboutirent à une rupture. L'Université Laval ouvrit à Montréal une faculté de Médecine distincte, mais la masse des étudiants montréalais resta fidèle à l'ancienne École.

Tous ces conflits se rejoignaient. Dans l'ensemble, Montréal était avec Mgr Bourget et l'École de Médecine, Québec avec Mgr Taschereau et l'Université Laval. Les conservateurs favorisaient le projet d'université montréalaise, et les libéraux jugeaient l'Université Laval très suffisante à la tâche. L'évêque des TroisRivières se tenait aux côtés de son chef de file et ami. Les rivalités de personnes, de partis, d'institutions et même de villes 
se greffaient, enchevêtrées, sur le conflit d'idées générales. Il y eut dans chaque camp des dissidences, des foyers de résistance. A Québec, le Cercle Catholique, avec Jules Tardivel parmi ses animateurs, formait une cellule ultramontaine, une petite troupe d'éclaireurs - on dirait aujourd'hui une cinquième colonne bataillant au cour du pays ennemi. Dans la région montréalaise, l'actif et influent curé Labelle se trouvait en discorde avec $\mathbf{M g r}$ Laflèche qui, par hostilité de principe envers les jeux de hasard, combattait son projet d'une grande loterie en faveur de la colonisation. Puis, Mgr Laflèche voulut créer une école normale - entièrement religieuse - aux Trois-Rivières. L'École normale Jacques-Cartier de Montréal et l'École normale Laval de Québec s'alarmèrent de ce projet qui leur susciterait une concurrence, et s'y opposèrent de toutes leurs forces. L'École normale JacquesCartier fournit un point d'appui aux adversaires de Mgr Laflèche à Montréal.

Le diocèse des Trois-Rivières suivait son évêque, à l'exception du Séminaire de Nicolet, qui luttait pour son existence. Le Séminaire de Nicolet demanda au Saint-Siège la division du diocèse des Trois-Rivières et l'érection d'un diocèse de Nicolet. Une alliance d'opportunité se souda entre les professeurs de Nicolet, l'Université Laval et le parti libéral. Tous les adversaires de Mgr Laflèche poursuivirent cet objectif : la division du diocèse des Trois-Rivières. Les émissaires des deux camps se succédèrent à Rome.

$\mathrm{Au}$ sein même du parti conservateur se produisirent de graves dissidences: celle de Georges-Étienne Cartier, puis celle de Chapleau. Chapleau, devenu premier ministre de la province, portait l'étiquette conservatrice. Mais c'était un conservateur de tempérament libéral. Nature bohème, il aimait la bonne chère, la vie facile, à la bonne franquette, et se sentait moralement plus près du libéral Mercier que des ultramontains de Boucherville et Trudel. Il appuyait l'Université Laval. Au cours d'un voyage en Europe, Chapleau dut donner à Rome un avis favorable à la division du diocèse trifluvien. Les ultramontains, ces âmes de feu, combattirent Chapleau sans merci. L'un d'eux, probablement le sénateur Trudel, publia, sous le pseudonyme de 
Castor, une brochure retentissante contre Chapleau. Les ultramontains reçurent le sobriquet de « castors ».

Mgr Laflèche liait en un fasceau toutes les difficultés religieuses, pour dégager leur commune nature. Sous les alliances d'opportunité, il discernait une lutte entre deux courants d'idées. Les uns veulent garder au Canada français son caractère religieux et y maintenir la prépondérance de l'Église. Ils veulent à tout prix empêcher les idées avancées, quasi triomphantes en Europe, de se répandre au Canada. Les autres croient le danger illusoire et trouvent les ultramontains d'une étroitesse d'esprit néfaste; ils sont flanqués d'un groupe où l'on souhaite, ouvertement ou secrètement, la propagation des idées avancées. De détail en détail, de polémique en polémique, on perd de vue les grands principes, mais tel est bien l'essentiel. Ainsi qu'il est de règle dans les conflits doctrinaux, où l'on cherche à façonner les esprits, chaque camp voulait s'emparer des écoles; et c'est pourquoi les batailles marquant cette guerre se livraient sur des questions scolaires et universitaires.

\section{LA DIVISION DU DIOCÉSE}

L'objectif immédiat de la coalition formée par les adversaires de Mgr Laflèche restait la division du diocèse des TroisRivières. Ce serait la pierre de touche. Un triomphe pour les uns, un désastre pour les autres. Mgr Taché, qui ne cessait d'encourager son ancien compagnon de l'île-à-la-Crosse, écrivit de Saint-Boniface au cardinal Simeoni, préfet de la Sacrée Congrégation de la Propagande:

...Toutes les mauvaises doctrines font école au Canada comme en Europe; ne pas convenir de cela, c'est s'endormir ou s'aveugler sur la situation réelle, ou vouloir endormir les autres ...

... La demande de la division du diocèse des TroisRivières ne peut pas paraître, à moi et à des milliers d'autres avec moi, autre chose qu'un acte de vengeance et un immense scandale...

Tardivel écrivit dans la $V$ érité :

Ennemis déclarés de l'Eglise, francs-maçons avérés, libéraux avancés, libéraux mitigés, gens imbus de 
l'esprit du siècle, tous ceux qui ne sont pas franchement et sincèrement catholiques, les indifférents, les tièdes, les mondains, toute l'armée du mal en un mot, s'agite dans l'impatience la plus manifeste. Tout ce monde-là soupire après la division du diocèse des Trois-Rivières.

D'un autre côté, il est certain que pour l'immense majorité du clergé de la province, nous pourrions dire la presque totalité du clergé, pour les laïques éclairés et pieux, cette division serait un désastre matériel et moral ...

C'est que, de part et d'autre, dans l'armée du mal comme dans l'armée du bien, Mgr Laflèche, évêque des Trois-Rivières, est considéré comme le champion le plus en vue des doctrines romaines, comme l'adversaire le plus déterminé de la franc-maçonnerie et du libéralisme. La division de son diocèse serait considérée comme une humiliation infligée à ce vaillant prélat, à cet intrépide défenseur des droits de l'Eglise et de la pureté de la doctrine...

En 1885 - l'année de l'affaire Riel - le Saint-Siège décrète la division $d u$ diocèse des Trois-Rivières et l'érection d'un diocèse de Nicolet.

Les ultramontains eurent l'impression d'un écrasement. Beaucoup eurent une instinctive réaction de révolte. Mgr Gravel, premier évêque de Nicolet, venant prendre possession de son siège, traversa Trois-Rivières comme une ville morte: tous volets fermés, personne dans les rues.

Mgr Taché écrivit à celui qu'il considérait comme un frère: «Préparez votre pastorale pour votre clergé et vos fidèles. Elle ne contiendra pas l'ombre d'une plainte ni d'un reproche...»

ROBERT RUMILLY, de l'Académie canadienne-française. 